\title{
Participation of Students in the Project Valorbio
}

\author{
A Case Study to Accelerate the Implementation of Sustainability Principles \\ in the Curriculum
}

\author{
Dina M. R. Mateus \\ Technology, Restoration and Arts Enhancement Centre (Techn\&Art), Instituto Politécnico de \\ Tomar, Tomar, Portugal \\ Henrique J. O. Pinho \\ Smart Cities Research Center (Ci2), Instituto Politécnico de Tomar, Tomar, Portugal \\ Isabel M. D. P. Nogueira \\ Smart Cities Research Center (Ci2), Instituto Politécnico de Tomar, Tomar, Portugal \\ Manuel A. N. H. Rosa \\ Technology, Restoration and Arts Enhancement Centre (Techn\&Art), Instituto Politécnico de \\ Tomar, Tomar, Portugal \\ Marco A. M. Cartaxo \\ Smart Cities Research Center (Ci2), Instituto Politécnico de Tomar, Tomar, Portugal \\ Valentim M. B. Nunes \\ Smart Cities Research Center (Ci2), Instituto Politécnico de Tomar, Tomar, Portugal
}

Submitted: 01-Sep-2019

Revised: 20-Nov-2019

Emerald allows authors to deposit their AAM under the Creative Commons Attribution Noncommercial International Licence 4.0 (CC BY-NC 4.0). To do this, the deposit must clearly state that the AAM is deposited under this licence and that any reuse is allowed in accordance with the terms outlined by the licence. To reuse the AAM for commercial purposes, permission should be sought by contacting permissions@emeraldinsight.com.

\section{Abstract}

Purpose - The present work describes the case of the Valorbio research project, in which students of different high-level programs were involved in the experimental work and in the dissemination of results in collaboration with the research team.

Design/methodology/approach - The inclusion in higher education curricula of content related to the sustainable development should be a preferred mechanism for the dissemination of good practices of sustainability. Another equally important way to achieve this is to involve students in research projects that seek solutions to the societal challenges related to sustainable growth. The Valorbio project aims to meet the needs for treating and reusing wastewater and solid waste. Its main goal was the development of modular systems for wastewater treatment based on constructed wetlands, exploring the possibility of the treatment systems being composed of solid waste and by-products from significant industrial sectors. 
Findings - The students' contribution to the research work was relevant, and simultaneously allowed them to acquire skills on sustainable development. Additionally, the students contributed to the dissemination of the results. The Valorbio project can thus be considered a successful application of the concept of project-based learning, as a way to include sustainability issues content in the higher education curricula.

Originality/value - The applied experimental work had an original approach regarding the equipment design, the waste materials valuation, as well as the integration of waste treatment processes in the circular economy paradigm. This paper is the first reported project-based learning experience involving students of short-cycle technical-professional programs in partnership with first and second-level students and a research team.

Keywords: Circular Economy; Constructed Wetlands; Education for Sustainability; Project-based Learning; Waste Valorisation; Sustainable Development.

Paper type: Case study 


\section{Introduction}

Higher education institutions (HEIs) have a fundamental role in society regarding sustainability issues as they are the prime active agents promoting the dissemination of scientific knowledge, being the natural leaders in the changes of awareness of the societies influenced by them. Thus, HEls are the most likely vehicles to bring about attitude changes in individuals, communities, companies and institutions, necessary to achieve sustainable development (Purcell et al., 2019; Nunes et al., 2018; Díaz-Iso et al., 2019; Shawe et al., 2019; Leal Filho et al., 2019).

It is only natural that HEls are considered stakeholders and role models in their communities in many aspects, but in particular in social and environmental responsibility. This can be done by a close cooperation with the community, not only by the spreading of knowledge, but also by serving and helping the society when needed (Findler et al., 2019; Purcell et al., 2019; Nunes et al., 2018).

Recently, HEls have been called upon to commit to the development of sustainable practices by the United Nations Conference on Sustainable Development "Rio+20". As a result, many HEls around the world are implementing sustainable practices on their campi (Cheang et al., 2017; Pedersen et al. 2017; Tangwanichagapong et al., 2017; Farinha et al., 2019).

The inclusion in higher education curricula of content related to the sustainable growth of society should be considered as a preferred mechanism for the dissemination of good practices in the context of sustainability (Fonseca et al., 2018; Mendoza et al., 2019). Another equally important way to achieve this is to involve students in applied research projects that seek solutions to the societal challenges related to sustainable growth. The project-based learning (PBL) approach can be a powerful tool to introduce and motivate the students for the sustainable development issues, promoting the interdisciplinarity and the cross-over of skills among HE programs (Dobson and Tomkinson, 2012; Caniglia et al., 2016; Fuertes-Camacho et al., 2019; Hero and Lindfors, 2019).

Biological-based technologies for waste treatment and recovery are essential to promote the sustainable development and to potentiate the circular economy (Di Maria et al., 2016; Gherghel et al., 2019; Masi et al., 2018; Moretti et al., 2018). Research projects on biological-based technologies could be a relevant framework for PBL implementation.

Constructed wetlands (CWs) represent an example of biological and eco efficient technology for wastewater treatment and recovery (Kadlec and Wallace, 2009; Wu, et al., 2015a). The project described in this work entails the improvement of CWs, exploring routes to increase the sustainability of CWs and their contribution to a circular economy. Four-main contributions were highlighted: (i) the use of renewable raw materials in the assembly of CWs; (ii) the recovery of industrial solid waste as CWs filling media; (iii) the recovery of wastewater; (iv) the valorisation of the vegetation cultivated in the CWs.

The Portuguese HE includes since 2014 a new type of short-cycle programs, entitled technicalprofessional programs (TeSP), mainly focused on developing professional skills, which changed the scenario of the HE framework. Consequently, the structure, learning methodologies and learning outcomes of the programs in the Polytechnic HE subsystem can be subject of optimization, including the opportunity to involve the participation of students in applied research activities and promote the reinforcement of soft skills. Concerning the relevance of the sustainable growth and circular economy concepts, applied research may be a way to solve in a 
short-time the absence of those concepts in the curricula contents, and may be a driven-force to promote its formal inclusion in the future.

This paper reports for the first time a project-based learning experience involving students of short-cycle technical-professional programs, extending existing knowledge on sustainability issues for this kind of program. This was done in partnership with students of first and secondlevel programs and with a research team in the development of an applied research project. Even though project-based learning can be a powerful tool for developing students' skills in addressing sustainability challenges, the results may be constrained by the knowledge and skill level of undergraduate students. Creating project teams that also include graduate students can be a way to overcome this constraint.

The paper was organized in 6 sections after this introduction: (i) the description of the structure of the Portuguese HE degrees; (ii) the description of the research project which consisted in the host framework for student's participation and linkage to the sustainable growth and circular economy principles; (iii) a short description of the constructed wetlands technology; (iv) the identification of the project's research activities where the students were integrated in the PBL approach focused in this paper; ( $v$ ) a results and discussion section, describing in detail the student's participation and the main learn outcomes obtained; (vi) the conclusion section.

\section{Structure of academic degrees at Portuguese Higher Education System}

The Polytechnic Institute of Tomar (IPT) is a Higher Education Institution located in the Middle Tagus Region (in Central Portugal) which assumed from the very beginning that several gaps needed to be filled for the development of the Region in which it operates. It offers programs in domains such as Arts, Sciences, Management and Engineering that creates an atmosphere particularly suitable for the implementation of sustainable development principles, since this is a concept that is transversal to all those areas.

The Higher Education System in Portugal is a binary system that encompasses two subsystems: the university and the polytechnic (Figure 1). The differentiation between these two subsystems covers legal aspects related to the granting of academic degrees, careers and academic training. In the polytechnic institutions it is expected that the training of students has a more vocational approach. In order to achieve this, the acquisition of competences through courses of a technological nature, with a strong practical component, is privileged.

The structure of academic degrees at Portuguese Polytechnic Institutes, including the IPT, focuses in advanced technical training or professional oriented training. These studies are mainly organized into: Technical-Professional's Degrees (two years), Bachelor's Degrees (three years) and Master's Degrees (two years).

Most of these programs include supervised training periods either in the IPT or in national or foreign companies. All the programs of IPT are, since 2007, adapted to the Bologna principles. 


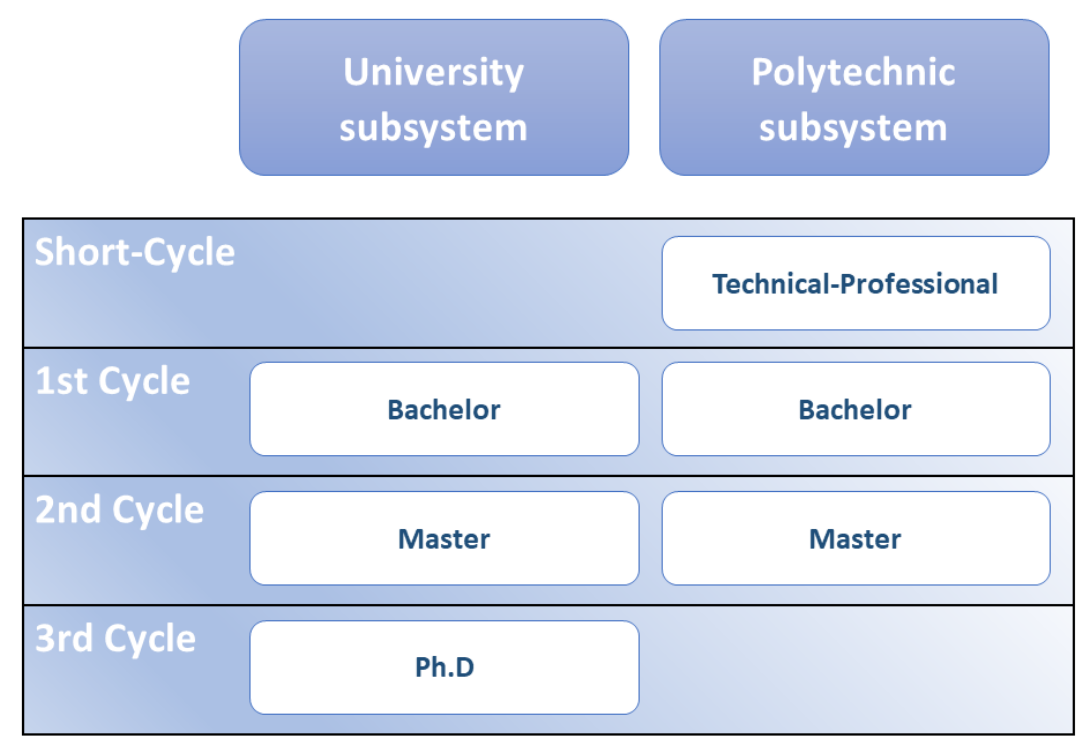

Figure 1 - Structure of the Portuguese HE system.

The Technical-Professional Higher Programs (TeSP) are offered only by the Polytechnic subsystem. These programs correspond to the $5^{\text {th }}$ level of the European Qualifications Framework, which corresponds to a set of comprehensive, specialized, factual and theoretical knowledge in a particular area of study or work and awareness of the limits of this knowledge. Graduates can pursue studies for a first cycle program, bachelor's degree.

\section{Description of the Research Project Valorbio}

The Valorbio project - "Wastes valorization through modular constructed wetlands for wastewater treatment" - was co-financed by EU funds (POCI-01-0145-FEDER-23314). The project was developed over a period of 18 months, between July 2017 and January 2019, and aimed to improve the design, operation and sustainability of Constructed Wetlands. The applied experimental work involved three higher education institutions (The Polytechnic Institutes of Tomar, Coimbra and Portalegre) and one company (Palser - Bioenergia e Paletes, Lda.).

The project had four main objectives, which were fully achieved: (i) Designing, building and testing a system of modular CWs using wood raw materials in the structure to increase the sustainability of the CWs, reducing their impact on ecosystems and enabling the valorisation of the end-of-life structures; (ii) Testing residual materials and by-products generated in the region as a filler for the modular CWs (for example rock fragments and other materials used in construction, coal slags from power plants, waste from forestry activities, agriculture and agrifood industries, among other solid residues); (iii) Evaluating the quality of the wastewater after treatment by the CWs and defining the conditions in which the water can be reused or valorised, reducing water consumption and protecting fresh water resources (for example for irrigation, for floor and industrial equipment washing, or for algae production); (iv) Evaluating the potential and the conditions of valorisation of the vegetal biomass produced in the CWs (resulting from the regular pruning of the emergent parts of the macrophytes), namely as a source of renewable energy. 
Figure 2 shows the relationship between the main goals of the project:

1. The modular CWs consist in a wood structure filled with solid waste and planted with macrophyte plants;

2. The modular CWs can be designed to treat different types of wastewaters;

3. The treated wastewater can be recovered for irrigation, washing or algae cultivation;

4. The macrophyte biomass can be valorised for bioenergy and biorefinery applications; the end-of-life wood structures and the solid filler can also be valued.
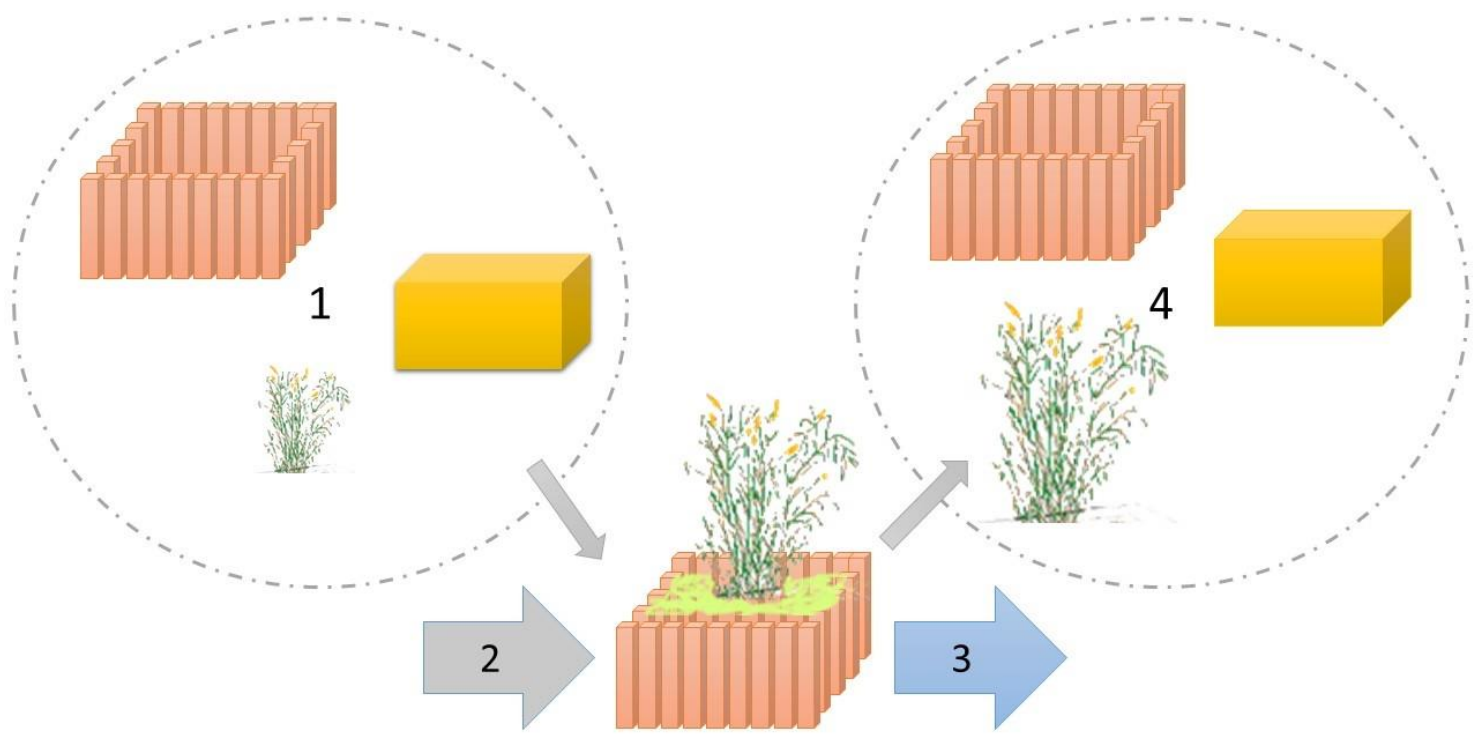

Figure 2 - General scheme of the project's objectives. The number meaning is described in the text.

The project's objectives fit the paradigms of Circular Economy, Bioeconomy and Sustainability, and explore and develop the concept of "Waste to Treat Waste".

The demonstration of the functionality of the modular CWs filled with waste materials, and the potential to value the treated water and the vegetal biomass produced, contribute to nine of the seventeen Sustainable Development Goals proposed by the UN: Clean Water and Sanitation; Affordable and Clean Energy; Industry, Innovation and Infrastructure; Sustainable Cities and Communities; Responsible Production and Consumption; Climate Action; Life Below Water; Life On Land; Partnerships for the Goals.

The results obtained also contribute to the response to three of the seven Horizon 2020 Societal Challenges: Food security, sustainable agriculture and forestry, marine and maritime and inland water research, and Bioeconomy; Secure, clean and efficient energy; Climate action, environment, resource efficiency and raw materials.

The project also falls into seven of the Priority Domains of Smart Specialization: Agri-food; Water and Environment; Energy; Forest; Materials and Raw-materials; Production Technologies and Process Industries; Production Technologies and Product Industries.

\section{Project Activities}

The applied research undertaken consisted in ten main activities: 
- Activity 1 - Organization and planning of project's tasks and preparation of the experimental activities;

- Activity 2 - Preliminary laboratory-scale studies in which the potential of several solid waste materials was evaluated to be used as $\mathrm{CW}$ filler;

- Activity 3 - Evaluation of the performance of small-scale (sub-pilot) CWs prototypes to evaluate the performance of the materials selected in Activity 2 and the effect of operative conditions on the wastewater treatment efficiency and on the development of macrophytes;

- Activity 4 - Design and construction of modular CW systems using wood as the construction material for the equipment structure;

- Activity 5 - Monitoring of the wastewater treatment efficiency of a pilot-scale reference $\mathrm{CW}$ and comparison with the performance of the modular CW monitored in Activity 6;

- Activity 6 - Monitoring of the wastewater treatment efficiency of a pilot-scale modular CW prototype whose filling consisted of a stratified mixture of waste solids and operative conditions selected and optimized in Activity 3;

- Activity 7 - Evaluation of the potential of water recovery for applications such as irrigation, washing and algae production after treatment by $\mathrm{CW}$ prototypes.

- Activity 8 - Assessment of the valorisation of the emergent parts of plants cultivated in the CWs (stems and leaves), namely for energy production (bioenergy applications);

- Activity 9 - Analysis of results, conclusions and proposal for future work;

- Activity 10 - Dissemination of the project activities and outcomes.

\section{Main Achievements}

The first objective of the project was successfully accomplished by designing a modular system for the construction of CWs based on structural elements built in renewable materials. The solution found was validated through the construction of pilot scale $\mathrm{CW}$ prototypes and a patent application was submitted (Figure 3).
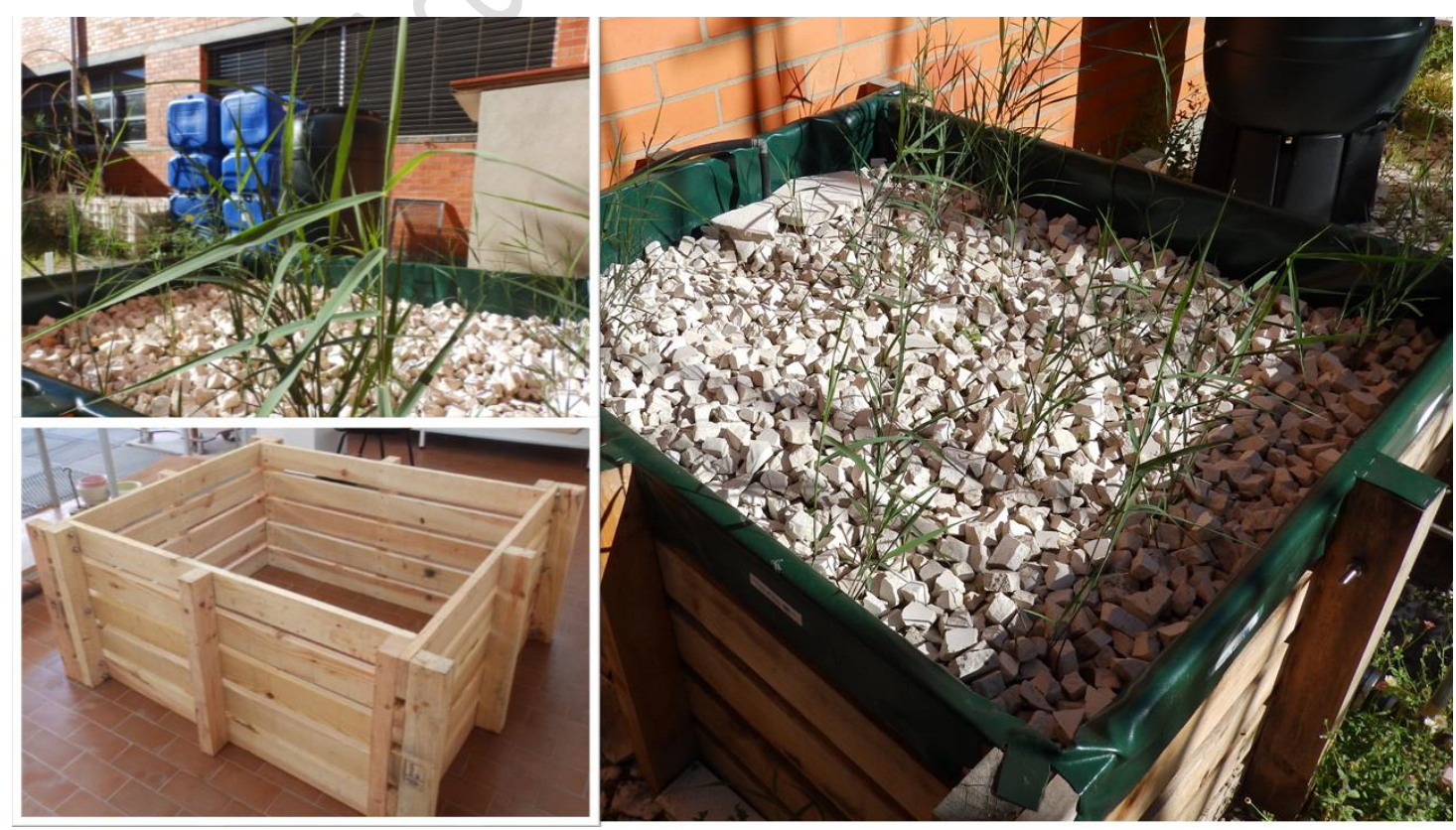

Figure 3 - Pictures of a modular wood-based CW. One of the inserted images shows the wood-based structure. 
A modular CW prototype was tested and used for treatment of both urban and industrial types of wastewater. It has been observed that the wastewater treatment performance is similar, or even superior, to that obtained with traditional systems. The prototype of modular CW was constructed with structural elements of pine wood. The use of wood valorises the endogenous resources of Portugal and has the advantage that the structures used can be also recycled for energy purposes.

To achieve the second objective, ten waste solid materials were tested. It was concluded after a first stage of laboratory-scale experimentation that five of these materials do not have the properties required to CWs fillers: Crushed eggshells; Dealcoholized grape pomaces; Olive seeds; Wood pellets; and Pine bark fragments. The remaining five materials have suitable physical and chemical properties for use in CWs (Figure 4): (i) Fragmented residues from Moleanos limestone extraction and transformation activities (a stone widely used as ornamental material in construction industry) have a significant capacity for the removal of phosphorus compounds present in wastewater; (ii) Clay brick fragments, a waste originated from crashed or nonconforming construction clay bricks, have a moderate capacity for the removal of phosphorus compounds and organic compounds present in wastewater; (iii) Coal slags, a waste from coal power plants, have demonstrated a significant capacity for the removal of organic compounds from wastewater; (iv) Cork granulates, a waste from cork processing industries, also demonstrated a significant capacity to remove organic compounds from the wastewater; (v) Snail shells, a waste from catering and food processing industries, led to ambiguous results, and it was decided to evaluate them in a second stage (laboratory-scale CWs).

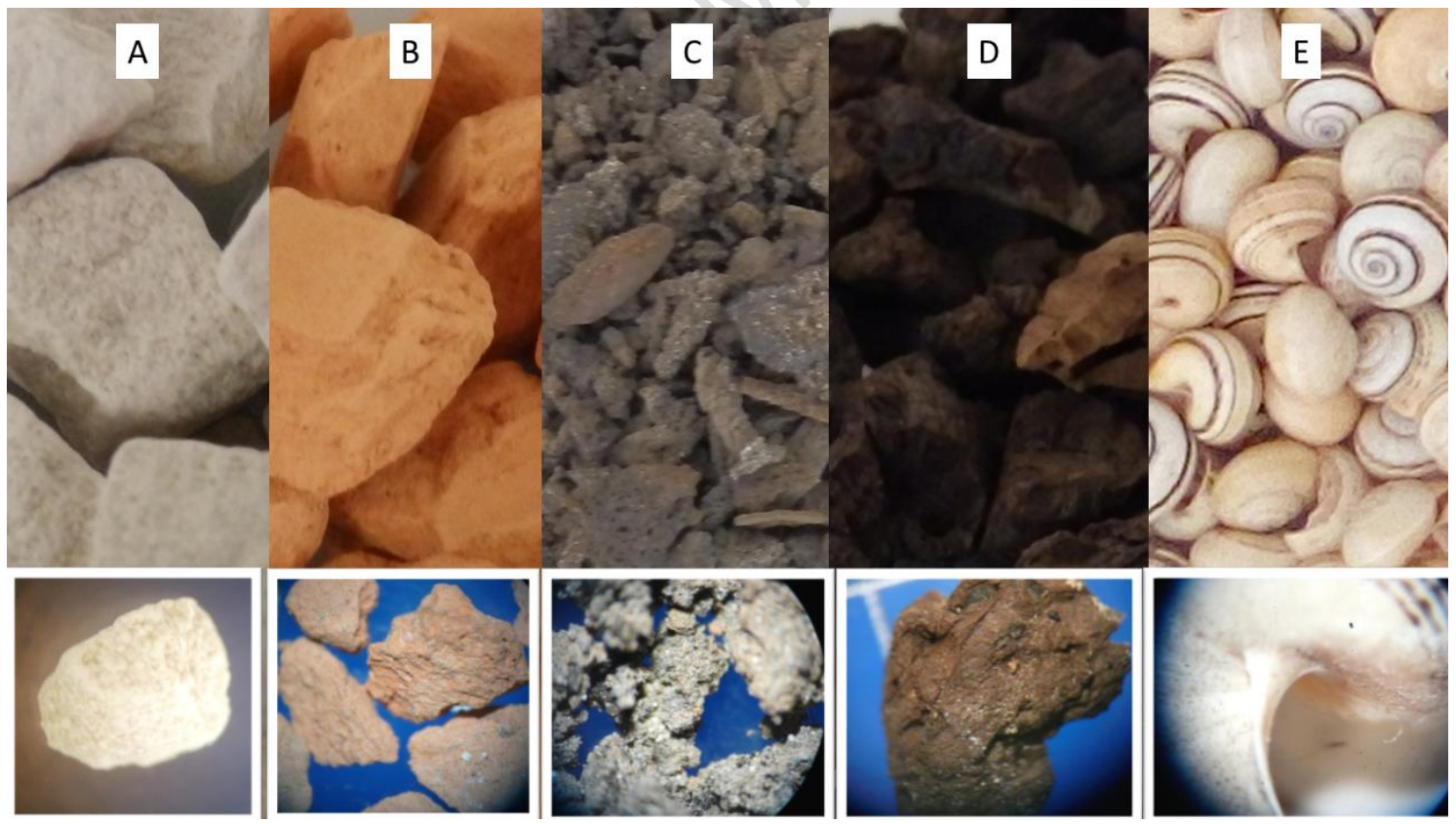

Figure 4 - Picture of the selected five waste materials. The inserted images are microphotographs. (A) Limestone fragments; (B) Clay bricks fragments; (C) Coal slags; (D) Cork granulates; (E) Snail shells.

In a second stage of experiments, small-scale CW prototypes were constructed filled in with three layers of solid waste (Figure 5A). Mixtures of the five waste materials selected in the first stage were used to gain benefits by combining different properties and pollutant removal 
capabilities. The lower and upper layers were composed, in each prototype, of limestone fragments and the intermediate one of the other four materials (Figure 5B).
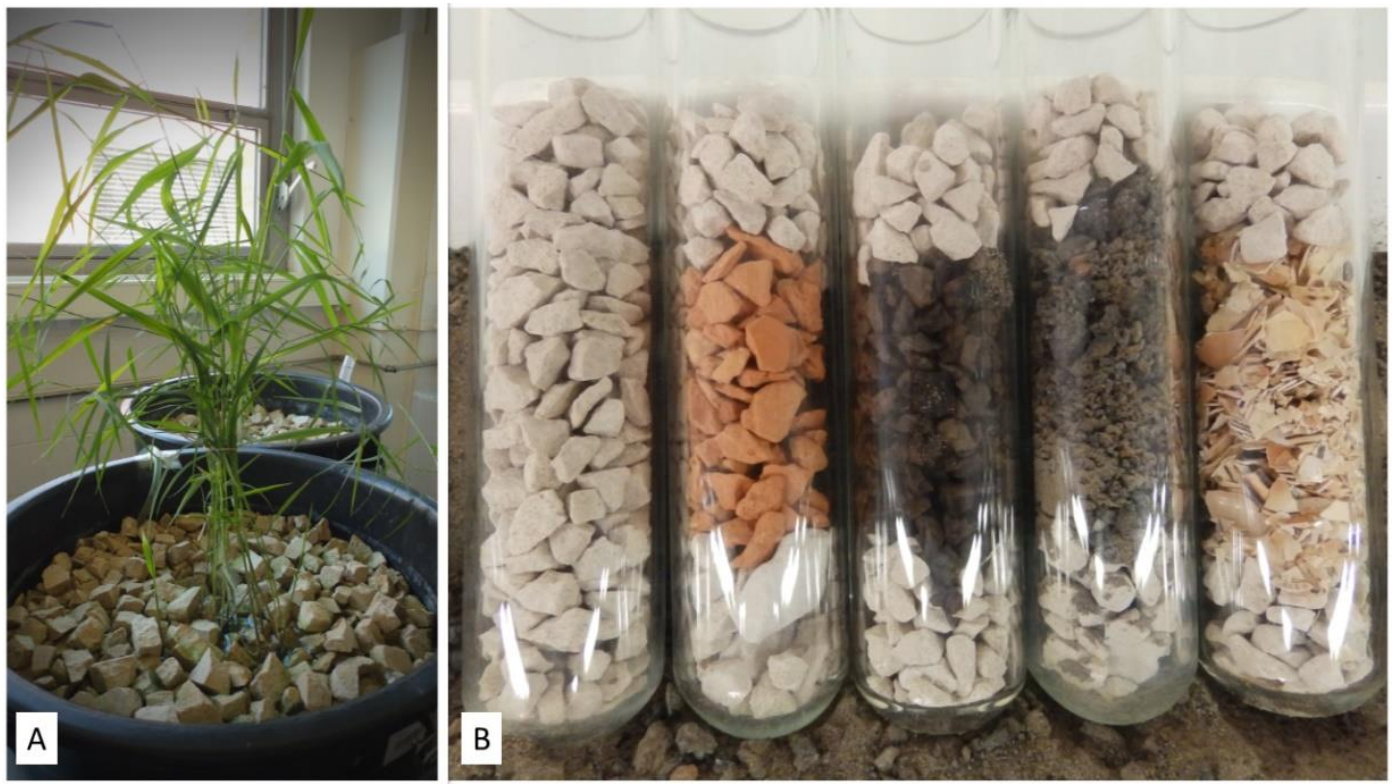

Figure 5 - (A) Picture of a small-scale CW prototype; (B) Waste solids stratification example.

It was found that the prototypes of CWs with the combination of limestone fragments and coal slag and with the combination of limestone fragments and cork granulates were the most efficient and regular in the treatment of wastewater of various types and composition, and under different operating conditions.

Following the study of the laboratory-scale CW prototypes, an additional set of prototypes with four filling layers was constructed, with the lower and upper layers consisting of limestone fragments and two intermediate layers of coal slag and cork granulates. The combined effect of the three materials proved to be efficient in treating various types of wastewater, including urban and industrial type.

To reach the third objective of the project, tests were carried out to valorise the water treated by the different CWs through tests of biomass algae production and irrigation of ornamental plants. Chemical and microbiological analyses were performed to evaluate whether the treated water fulfilled the necessary requirements to be used for aquaculture and irrigation purposes (Bourguignon, 2018; Portuguese Law DL236/98, 1998). Toxicity tests were also carried out to verify if the contact of the water with the waste materials could lead to the release of harmful substances. The results were satisfactory, and it may be deduced that the water can be used for algae production, watering of plants and washing of equipment and floors.

In order to reach the fourth objective, it was evaluated the calorific potential of the reeds planted in the prototypes CWs as well as pine wood, the material used in the structural elements of the CWs. Gasification tests of mixtures of reeds and pine wood were carried out at the Polytechnic Institute of Portalegre (Portugal), partner in the project. The results showed that it is advantageous to use a blend of $10 \%$ of reeds biomass and $90 \%$ of pine wood. Pine wood may consist of residues from wood industries and forest cleaning activities, and also from modular $\mathrm{CW}$ structures at the end of life. 


\section{Short description of the Constructed Wetlands technology}

CWs consisted in biological systems for wastewater treatment. The CWs are based on-synergetic processes and are composed by 3 major components: soil - plants - microbiota. CWs are contained and controlled variants of Natural Wetlands (Kadlec and Wallace, 2009). The use of CWs has become widespread and has begun to be implemented throughout the world for about four decades. However, CW technology continues to be the subject of many studies in order to better understand the complex natural mechanisms that are at the basis of its operation with the purpose of increasing wastewater treatment efficiency and improving its sustainability (Mateus et al., 2016; Mateus et al., 2018; Wang et al., 2017; Wu et al., 2015a; Wu, et al., 2015b; Wu, et al., 2015c).

CWs are commonly used as advanced treatment systems, also referred to as tertiary treatment, complementing the primary and secondary systems typically installed in municipal or industrial WWTPs. In tertiary treatment systems, the main purpose is to remove compounds that are more resilient to previous treatments, such as nitrogen and phosphorus compounds, and whose release into the water environment can cause harmful phenomena such as eutrophication of more sensitive watercourses. In some cases, CWs may even replace secondary treatment systems, depending on the characteristics of the wastewater, for example in some industries and small residential clusters.

The CWs consist essentially of three main components: (i) A bed, or basin, which usually consists of a pond excavated in the ground, but which can also be a tank built above ground level - the bed is waterproofed, usually with a geotextile membrane, and is provided with inlet and outlet pipes for water flow; (ii) A solid granular filler material, or mixture of materials, placed inside the bed - the filler material may be common soil, but it is more usual to use materials such as sand or gravel, and more recently, waste materials; (iii) Aquatic plants, usually referred to as macrophytes - the plants can be floating species or rooted in the filler material and can be submerged or emergent species.

Wastewater is treated in the CWs through several complex and interconnected mechanisms, the most important of which are the following: The retention into the filler material of substances present in the wastewater, by combining physical and chemical phenomena such as adsorption, precipitation, mineralization, sedimentation and filtration - these processes contribute mainly to the removal of dissolved and suspended inorganic compounds present in the wastewater; The assimilation of nutrients and micronutrients by the macrophyte plants the plants remove nitrogen, phosphorus and potassium compounds, called nutrients, and trace minerals, called micronutrients, directly from the water via their root system; The degradation and assimilation of biodegradable compounds by the naturally occurring microbial community in these systems, free in the water phase or growing in biofilms fixed on the roots of the plants and on the surface of the granular filler material.

CWs can be of three main types (Figure 6) or can be hybrid systems that combine more than one type or integrate other wastewater treatment technologies. 
(1)

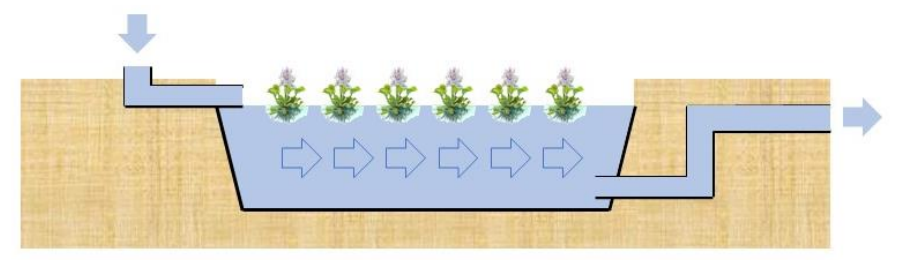

(2)

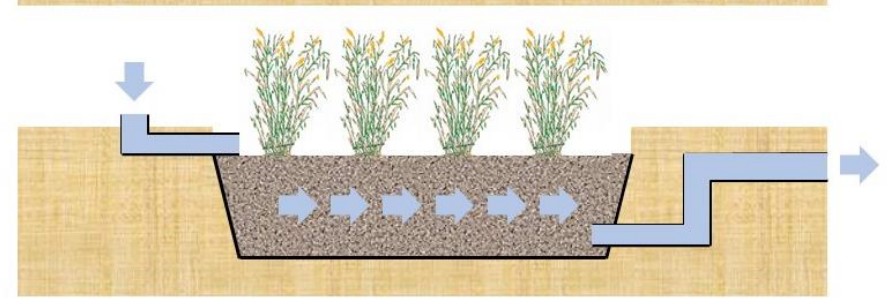

(3)

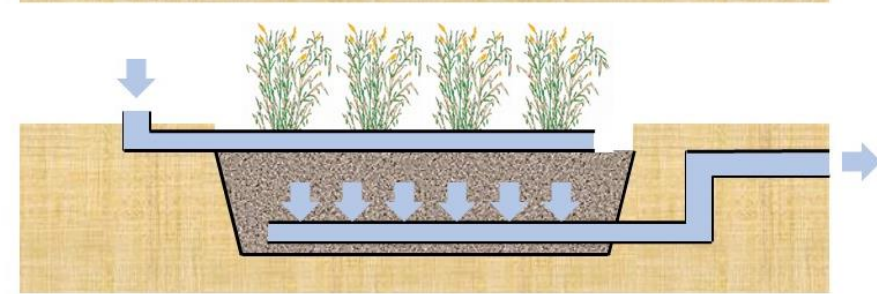

Figure 6 - Simplified drawings of the three main types of $\mathrm{CW}$.

(1) Free Surface Flow; (2) Subsurface Horizontal Flow; (3) Subsurface Vertical Flow.

The three main types of CWs are classified according to the flow of the wastewater under treatment: Free Surface Flow - The bed may or may not contain a filler material, but most of it is filled only with water - in this typology, floating macrophytes are commonly used, for example, water hyacinths (Eichhornia crassipes); Subsurface Horizontal Flow - the bed contains a granular filler with enough porosity to allow the wastewater to flow during the treatment - in this typology, emergent macrophytes are commonly used, for example common reed (Phragmites australis); Subsurface Vertical Flow - these are systems similar to horizontal subsurface flow, but the water circulates vertically along the filler, from the top to the bottom of the bed - in this typology emergent macrophytes are also used.

The typologies of subsurface flow are the most commonly used, and among them, the horizontal flow. In these typologies, the wastewater to be treated does not contact with the atmosphere, which reduces the risk of odour release and the development of undesirable insects.

\section{Methodology for the organization of student's participation in the project's activities}

Students of three different programs held at IPT participated actively in the applied research: Technical-Professional program in Environmental Quality (undergraduate level), First-level (Bachelor) program in Chemical and Biochemical Engineering and Second-level (Master) program in Chemical Technology.

Only the Master's program contains a specific curricular unit that explores Sustainable Development. The remaining programs do not include specific curricular units dedicated to sustainability issues, and the concepts of sustainable development are transversal to some curricular units within each program. 
The referred programs were selected because they correspond to a usual evolution path of students that decide continuing their studies. After completing the TeSP program the students can enrol in the Bachelor program, and then, after completing the Bachelor they can enrol the Master program.

The Valorbio project consisted of ten activities, as previously mentioned, but two of them were dedicated to project management procedures, and two activities were mainly developed in the project's partners facilities. A total of twenty-one students participated in six activities related to applied research and their contribution will be described in the following section. Three of the students were enrolled in a curricular internship of the TeSP program corresponding to 30 credits (ECTS). Eleven students were enrolled in the Bachelor program: three of them were enrolled in the Project course unit (12 credits) and the other eight students were enrolled in the Separation Processes in Biotechnology course unit (earning 2 credits). The remaining seven students were enrolled in the Bioprocess Engineering course of the Master program, earning 1 credit. The students from the different courses and programs worked in coordinated teams. Each team had performed different tasks, each being fundamental for the project final outcomes. All teams had been involved in the discussion of the experimental results. The students had been supervised by six teachers who were part of the project research team.

The activities were selected taking in to account the required skills to perform them and the program contents and objectives. Table 1 presents the select activities of the project, allocation of the students and expected contribution to development or improvement of learning outcomes.

The project activities extended over a period of 18 months, with students participating in six of the ten project activities on a time scale of about one year. 


\section{Table 1}

Allocation of the students to the Valorbio project' activities and expected contribution to development or improvement of learning outcomes.

$\mathrm{T}=$ Technical-Professional program in Environmental Quality; B = Bachelor program in Chemical and Biochemical Engineering; $M=$ Master program in Chemical Technology.

\begin{tabular}{|c|c|c|c|}
\hline Project activity & Research objective & Program & Developed skills \\
\hline 2 & & & \\
\hline \multirow[t]{2}{*}{$\begin{array}{l}\text { Evaluation of } \\
\text { physical and } \\
\text { chemical properties } \\
\text { of waste solids }\end{array}$} & \multirow[t]{2}{*}{$\begin{array}{l}\text { Evaluation of the potential to } \\
\text { use solid waste as CW's filling } \\
\text { material }\end{array}$} & $\mathrm{T}$ & $\begin{array}{l}\text { Carrying out physical and chemical analysis } \\
\text { Writing of simple reports } \\
\text { Preliminary discussion of experimental } \\
\text { data }\end{array}$ \\
\hline & & B & $\begin{array}{l}\text { Selection of adequate methods of analysis } \\
\text { Carrying out physical and chemical analysis } \\
\text { Writing of advanced reports } \\
\text { Detailed discussion of experimental data }\end{array}$ \\
\hline 3 & & & \\
\hline $\begin{array}{l}\text { Monitoring the } \\
\text { operation of small- } \\
\text { scale CWs' } \\
\text { prototypes }\end{array}$ & $\begin{array}{l}\text { Evaluation of the efficiency of } \\
\text { wastewater treatment by } \\
\text { prototypes of CW filled in with } \\
\text { recovered waste solids }\end{array}$ & $\mathrm{T}$ & $\begin{array}{l}\text { Carrying out physical and chemical analysis } \\
\text { Writing of simple reports } \\
\text { Preliminary discussion of experimental } \\
\text { data }\end{array}$ \\
\hline
\end{tabular}

B Selection of adequate methods of analysis Carrying out physical and chemical analysis Writing of advanced reports Detailed discussion of experimental data

Analysis of workflow and data gathering Supervision of laboratory experiments Writing of advanced reports Detailed discussion of experimental data Critical review of the obtained results

5 and 6

Monitoring the operation of pilotscale CWs
Evaluation of the efficiency of wastewater treatment by $\mathrm{CW}$ at pilot-scale and validation of activity 3 results
B Selection of adequate methods of analysis Carrying out physical and chemical analysis Writing of advanced reports Detailed discussion of experimental data

M Analysis of workflow and data gathering Supervision of laboratory experiments Writing of advanced reports Detailed discussion of experimental data Critical review of the obtained results Proposal of future work

Evaluation of the reuse of the treated wastewater
Evaluation of the potential to reuse the wastewater after treatment by the CWs

T Carrying out water quality parameters evaluation

Writing of simple reports

Preliminary discussion of experimental data

B Design of lab experiments

Carrying out research work Writing of advanced reports Detailed discussion of experimental data

10

Promotion of the project activities and results
Dissemination of the project activities and the obtained results
All
Writing of reports and communications Presenting to an audience Promoting results and conclusions 


\section{Results and discussion}

The main results consist in the effective involvement of students from the three-degree programs in the project's activities mostly focused in contributions to a sustainable growth, as well as providing students and evolving community education for sustainability.

The results and discussion are organized according the project activities and objectives described in the preceding section.

\section{Evaluation of physical and chemical properties of waste solids (Activity 2).}

The goal of the activity 2 consisted in the evaluation of the potential to use solid waste as CW's filling material. The physical and chemical properties of ten waste solids were evaluated. The waste solids interaction with water and aqueous pollutants were also studied.

The collaboration of students of the Technical-Professional program focused on the physicalchemical characterization of waste materials.

The students were led to understand the importance involving industries in the social objective of protecting the environment and improving the quality of life of the population through the sustainable management of solid wastes and water resources, using the concept of circular economy and the logic of using "waste to treat waste", exploring the possibility of treatment systems incorporating waste and by-products from many important sectors.

The students contacted with several techniques for the analysis and characterization of effluents and materials, namely nitrogen and phosphorus compounds and COD contents, and Langmuir isothermal modelling.

The students made observations of the waste materials in a petrographic microscope and in a stereoscope microscope, before and after being used in the treatment of wastewater, and prepared the samples to perform their characterization by Micro $x$-ray fluorescence $(\mu F R X)$ and Attenuated Total Reflection Fourier Transform Infrared Spectroscopy (FTIR-ATR).

In this way, the students were led to study the fundamentals of these techniques and analytical instruments and to find its practical application in the development of the project. They had to collect and prepare the samples, make the observations, compile and treat the spectroscopic data, and analyse and compare the effect of contact of the effluent with the materials. The students also critically evaluated the differences between the studied materials and the information that can be collected by the different techniques and how they can be used in the interpretation of the obtained results.

Finally, the students could directly apply some subjects addressed in several curricular units, such as Raw Materials and Natural Resources, Analysis and Removal of Pollutants, Solid Waste Management and Wastewater Treatment. The contents of these courses can be adjusted in the future with a higher focus in sustainability.

Students of the Bachelor program participated in the development and implementation of experimental techniques related to the analysis of specific pollutants in the wastewater. For example, the liquid-liquid partition of phthalic acid between water and organic solvents was evaluated as a case study aiming the appraisal of the potential for the removal of phthalate 
water contaminants class. The works were conducted in parallel with practical classes regarding the Separation and Purification of Biological Products.

A student of the bachelor program, undergoing his Final Project, has participated in the physical characterization of the waste solids properties such as true and bulk density, and size classification by sieve techniques. In cooperation with the above mentioned technicalprofessional students, the student also developed bench-scale assays which evaluated the leaching risk and the sorption potential of water pollutants by the tested waste solids. The developed work and the obtained results contributed to the selection of the most suitable waste solids to be used in further activities of the Valorbio project. This step required deep and critical thinking about the advantages and disadvantages of using solid waste as a means of filling CWs.

The involved students acknowledged that the reuse of solid waste as CW's fillers can contribute to increase the sustainability of wastewater treatment systems and to a circular economy of the waste.

\section{Evaluation of the performance of small-scale (sub-pilot) CWs prototypes (Activity 3).}

The performance of small-scale (sub-pilot) CWs prototypes was evaluated during the activity 3 of the Valorbio project (Fig. 6). The CWs prototypes were filled with mixtures of five selected waste solids among the materials tested in the activity 2 . The effect of operative conditions on the wastewater treatment efficiency and development of CWs vegetation was also studied.

A student undergoing his internship in the Technical-Professional program developed complementary work on the waste solids physical and chemical characterization. Samples of the waste solids used in the CWs prototypes, namely snail shells, cork granulates, coal slag, clay brick fragments and fragmented residues from Moleanos limestone, were observed by microscopy methods and analysed by $\mu$ FRX and FTIR-ATR. The observed data were compared with the results obtained in the Activity 2 . The observed modifications in the materials surface were discussed and related with the use in the CWs. Observation of the development of organic deposits at solid surfaces has been associated with the growth of the microbial community, which is essential for biological mechanisms of removal of pollutants by CWs.

Students of the Bachelor and the Master programs collaborated in the evaluation of prototype$\mathrm{CWs}$ removal efficiencies. The students participated in wastewater sampling procedures at inflow and outflow streams of each prototype and in the water analysis and results discussion. The analysis included total nitrogen and total phosphorous, $\mathrm{COD}, \mathrm{BOD}_{5}$ and additional water properties such as temperature, $\mathrm{pH}$, conductivity, colour and dissolved solids. The results were relevant to evaluate the waste solids potentiality as CWs' fillers and the potential to reuse the treated water.

The developed activities contributed to increase the student's skills in analytical methods and creative thinking on cleaner and greener solutions for wastewater treatment and recovery.

\section{Monitoring of pilot-scale CWs (Activities 5 and 6)}

The project's activities 5 and 6 were carried out simultaneously. The activity 5 consisted in monitoring the wastewater treatment efficiency of a pilot-scale reference $C W$ and the activity 6 consisted in monitoring the wastewater treatment efficiency of a pilot-scale modular CW prototype whose filling consisted of a stratified mixture of waste solids and operative conditions selected and optimized in activity 3 . 
As in activity 3, the monitoring consisted of the regular collection of samples of the input and output streams of both CWs, and consequent analysis. Students of the Bachelor and the Master programs participated actively in the research activities.

The results were relevant to validate in real conditions the use of waste solids as CWs' fillers and the reuse of the treated water. The use of solid waste as a filling medium for CWs and the reuse of treated wastewater are important contributions to increase the sustainability of CWs.

\section{Evaluation of the potential to reuse the treated wastewater (Activity 7)}

The analysis of the treated water carried out in the activities 3, 5 and 6, gave good indications for the water reuse. To validate that potentiality, experiments were conducted in the activity 7 to validate the reuse of treated wastewater for applications such irrigation and algal biomass production. In addition, ecotoxicity tests using bioindicators were carried out.

The students of the Technical-Professional program participated and significantly contributed to the experimental activities consisting on ecotoxicity tests using bioindicators.

The principles behind such ecotoxicity tests are based in the understanding that the amount of a substance in the environment (its environmental concentration) is proportional to its harmful effect in an organism. The relationship between the dose and its toxic effect is known as doseeffect relationship. The different strategies for the absorption of toxicants from the environment and their effects on organisms can be used to predict the effects that a toxic agent might have on the environment if a set of representative organisms of the local fauna or flora is tested. These tested organisms are called bioindicators.

Several toxicity tests were performed with lettuce seeds of the Lactuca sativa species to understand the impact that the wastewater treated in the different CWs may have if used in the irrigation of such vegetables. The students have prepared all the necessary solutions, placed twenty seeds and $4 \mathrm{ml}$ of effluent in each Petri dish and done three repetitions for each tested effluent (Figure 7A). All the non-germinations were counted, and the germinations lengths were measured. Some samples of the treated wastewater had more impact on the seeds gemination and growth than others, as expected.
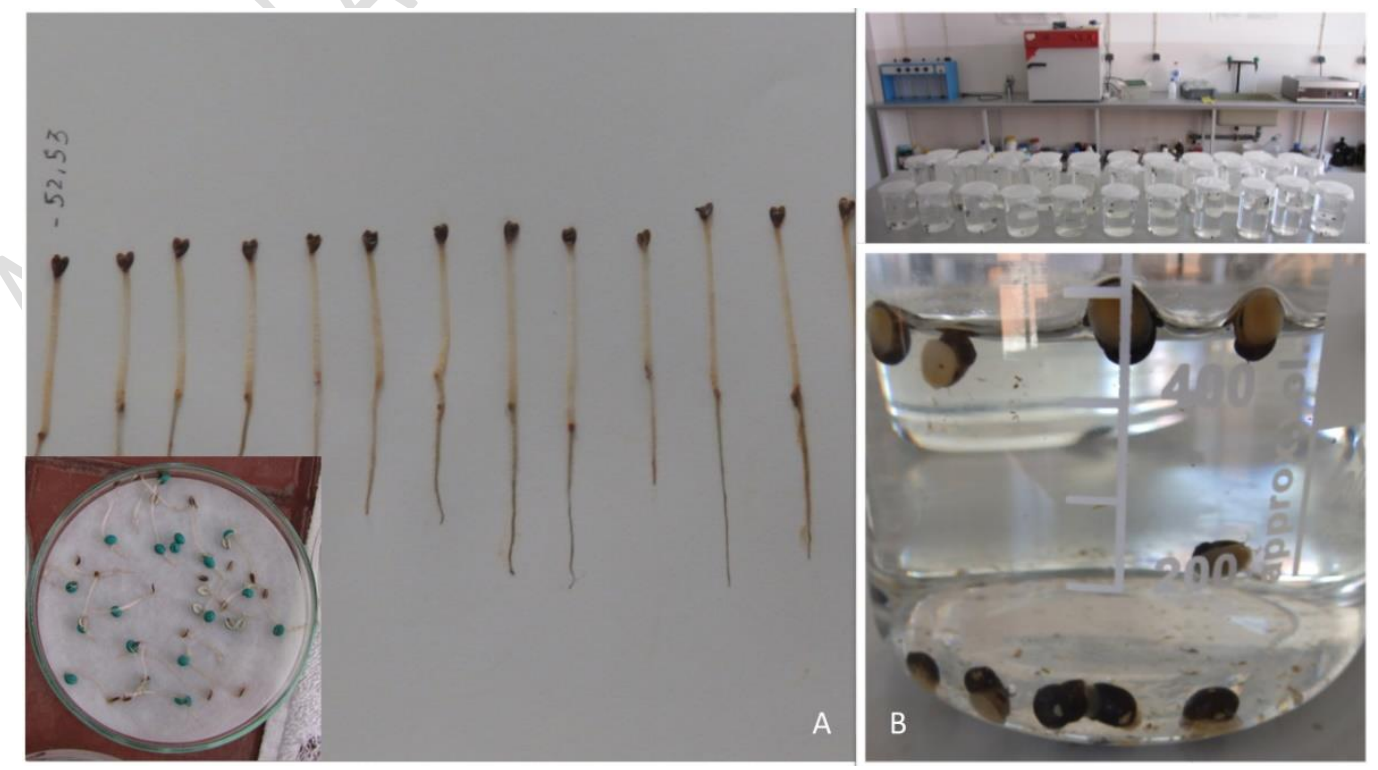

Figure 7 - (A) Ecotoxicological tests: Details of the germination inhibition tests with lettuce Lactuca sativa; (B) Details of one of the tests performed with snails of the Lymnaeidae family. 
Additional ecotoxicity tests with water snails were carried out. Snails of the Lymnaeidae family, which are abundant in the local rivers, were collected by students from the environment fresh water. These snails were the other bioindicator used, in this case to understand the impact that the wastewater treated by the different CW's may have in the rivers, if the wastewater is released in the environment after the treatment. The snails were placed in groups of ten elements in 2 litre beakers with one repetition for each treated effluent. The number of deaths were counted at the end of 28 days of exposure to the effluents (Figure 7B). The effluent that had a lower impact on the snails was used in another test, exposing the organisms to increasing dilutions and to a control test. After seven days of exposure the effects were studied, to understand which dilution of the treated wastewater was required to eliminate the impacts in the environment or to understand if the receiving watercourses provide enough dilution to prevent impacts.

With such kind of laboratory and field work, the students developed skills to understand the possible interactions resulting from the presence of xenobiotics in the environment, access the possible environmental risks, and evaluate the conditions to safely recirculate the water back to the environment.

Students of the Bachelor program, particularly a student within an international study-mobility program, carried out experiments to evaluate the potential of reusing the wastewater treated by the waste solid filled CWs' prototypes for irrigation purposes.

An experimental setup consisting in a set of small pots filled with regular soil and planted with Tagetes patula L. (French Marigold, Figure 8A) were regularly irrigated under controlled conditions with tap water, tap water with dissolved fertilizer and CW's treated wastewater. The plants growth indicators were monitored and recorded by the student.
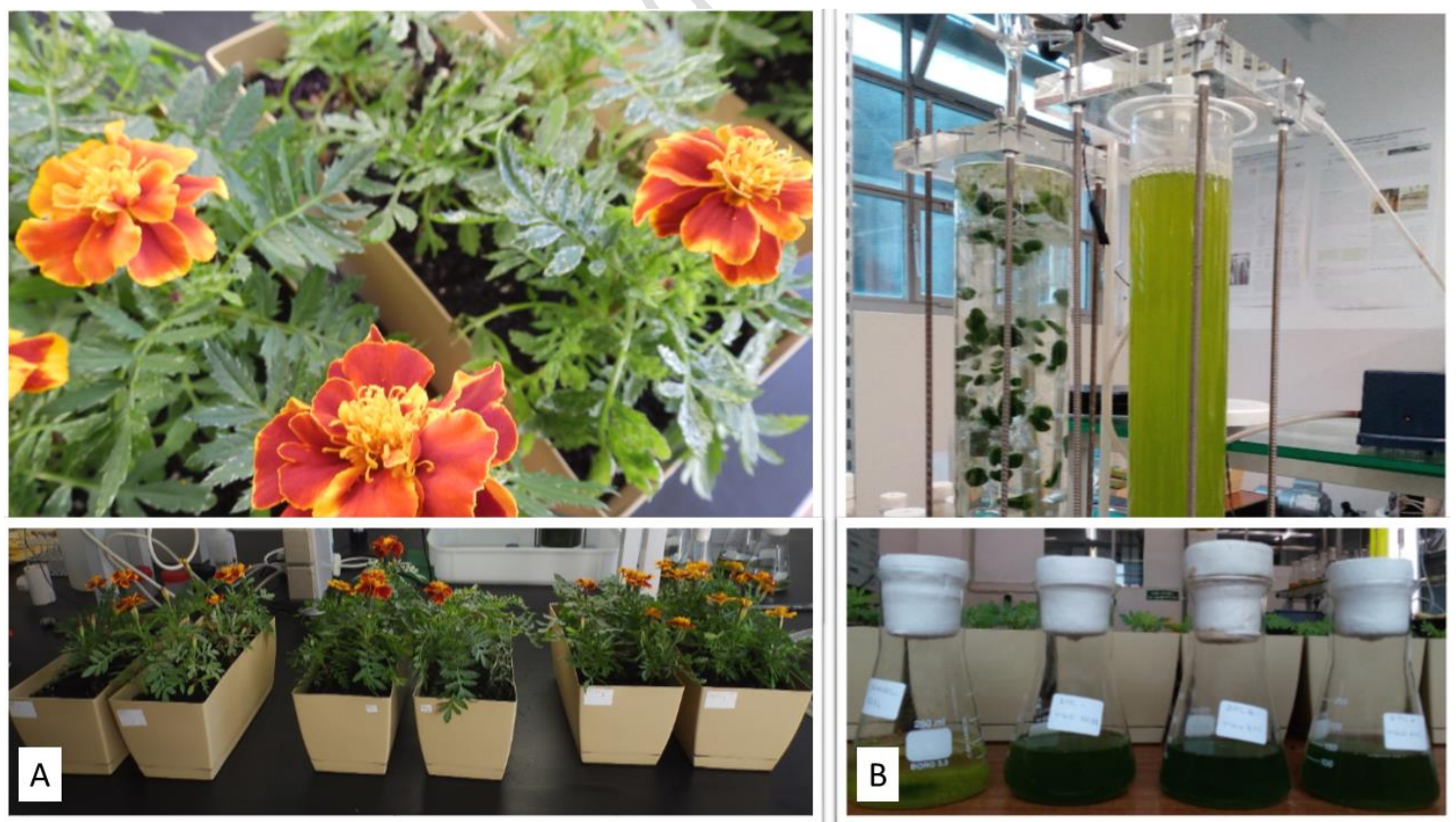

Figure 8- (A) Irrigation experiments with French Marigold plants; (B) Reuse of the treated wastewater for cultivation of micro and macroalgae.

It was observed that the plants adapted very well to the irrigation with the CWs' treated wastewater, presenting at the end of this period a healthy appearance. This led to the conclusion 
that it is possible to reuse the treated wastewater for the cultivation of ornamental plants, without the need of artificial fertilizers. The reused water contains a nutrient and mineral content that was enough to ensure the plant growth.

The students observed that it is possible to avoid the excessive use of various natural resources, not only water, but also minerals such as phosphorus and nitrogen compounds, which are the main constituents of synthetic fertilizers. Reducing the use of synthetic fertilizers in agricultural irrigation, which are one of the main sources of fresh water contamination, reduces the risk of adverse phenomena such as eutrophication of watercourses.

The presence of nutrients and minerals in the treated wastewater can also allow the reuse of water as a culture media for growing algal biomass. Algae, organisms that live in aquatic environments, are capable of photosynthesis and develop using sunlight and capturing atmospheric carbon dioxide. Microalgae reproduce very rapidly and can generate large amounts of biomass, including added-value substances, in a short time. Algae have the great advantage that they can be produced without the use of agricultural soils and therefore do not compete with food and feed production, which is often pointed out as a disadvantage, as is the case of agricultural crops intended for production of biofuels. The production of algae requires the use of high amounts of water and can thus be a disadvantage for the generalization of their production. Reusing treated wastewater for algae growth allows overcoming this disadvantage and making production more sustainable.

Students of the Master program participated in the experimental activities carried out to evaluate the reuse of the wastewater treated by the CWs prototypes in the cultivation of microalgae. Four species of algae were used. The microalgae Chlorella sp., the macroalgae Cladophora aegagropila belonging to the chlorophyta division, and a cyanobacteria (Anabaena $s p$.). Cultures were also carried out with mixed microalgae populations isolated from the CWs itself, as such already adapted to wastewater, with predominant species of the genus Scenedesmus sp.. The algal cultures in the CWs effluent were carried out in Erlenmeyer flask and bubble column reactor (Figure 8B), with natural light cycle and at various temperatures.

The students observed that the wastewater treated by the CWs prototypes ensured adequate conditions for the growth of the algae, and in most cases, the productivity obtained was higher in relation to the cultures grown in a synthetic medium.

With the results obtained the students observed that the reuse of treated wastewater, particularly when it still contains nutrients, is an example of circular economy and has many advantages, such as:

- Reduction of fresh water consumption;

- Decrease of discharges in water resources, which reduces the risk of eutrophication of watercourses;

- Reduction of the consumption of nutrients and minerals, particularly of some already scarce, such as phosphorus compounds.

\section{Dissemination of the project activities and outcomes (Activity 10).}

To publicize the activities and results of the project, with special focus on the contributions to the sustainable development and a circular economy, several actions were carried out. Students of the three programs participated actively in promotion sessions and workshops. The students 
collaborated in guided visits to the project' labs and CWs prototypes, welcoming students from other schools in the region and from other levels of education, and the community in general. The students also had a dynamic role in spreading the information, either by personal contact or by social media.

The complete project activities were presented and discussed in a session open to the entire local community, with emphasis on the concepts of sustainable growth and circular economy (Figure 9).

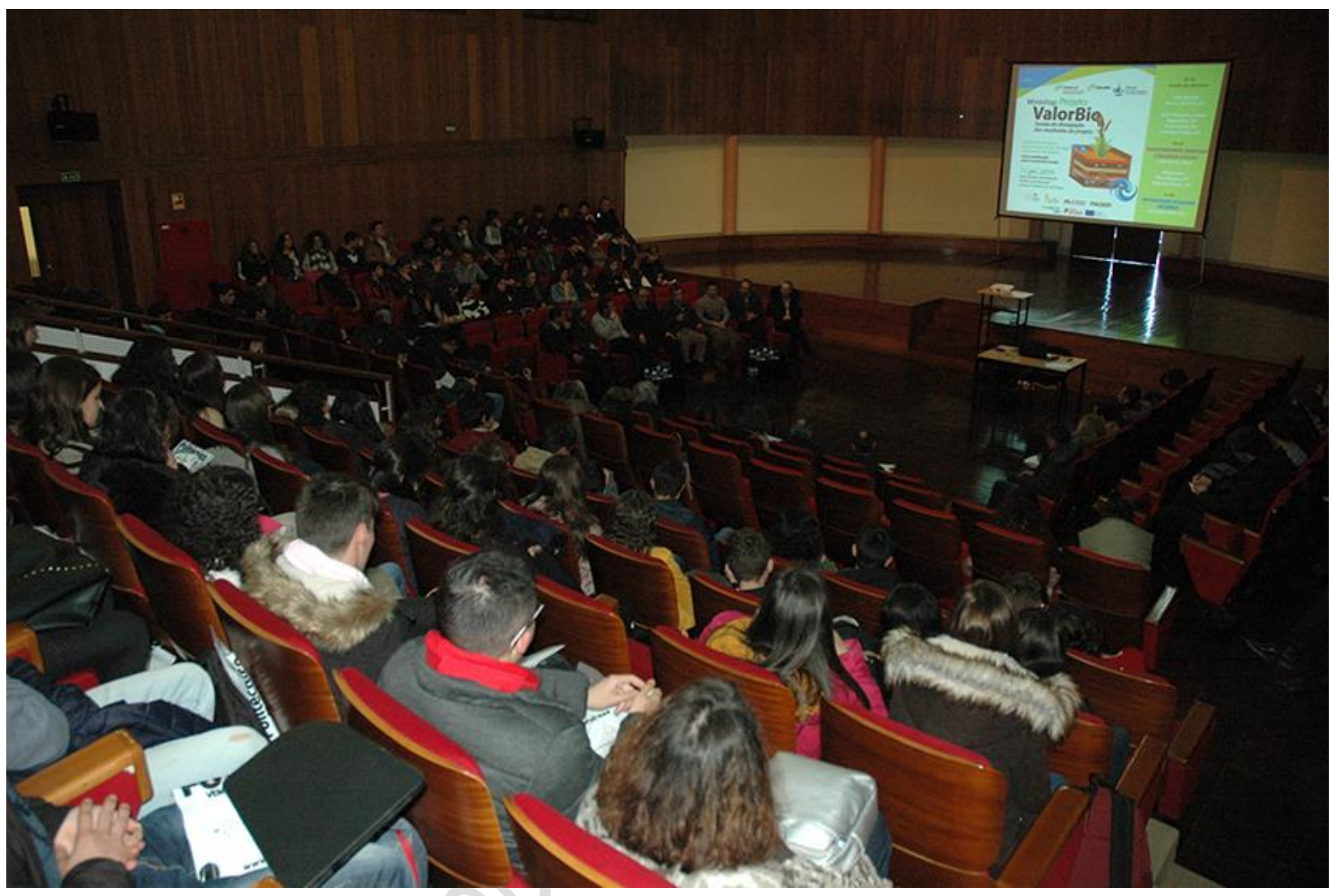

Figure 9 - Picture of the open session for dissemination of project's activities and results and to promote sustainable development and circular economy concepts.

It was observed that all involved students in the project activities acknowledged that the treatment of wastewater by greener systems can contribute to a sustainable development. In addition, they recognized that waste solids can be valued as filling media for CWs and the treated wastewater can be reused for irrigation and algae cultivation, reducing the consumption of fresh water, fertilizers and valuable micronutrients, as a real example of circular economy. Moreover, the students effectively acted as dissemination vectors of knowledge for a sustainable growth.

It was also realized that involving students in the applied research activities contributes to achieve learning outcomes related to sustainability in a real-world environment, and promotes the development of team work experience.

The main issues concerning the students' participation in the project was a lack of previous knowledge on sustainability and circular economy concepts, and organizational barriers to provide compatibility between the project's schedule and the programs' schedules. Students' enrolment in project-based learning actions can benefit from future improvements in the coordination between the programs' contents and the project's schedules and activities. 


\section{Conclusions}

The students that participated in the Valorbio project contributed effectively for the developed research work. During their participation, the students' concerns with issues that limit a sustainable growth and their knowledge on a circular economy paradigm were clearly improved.

Applying the project-based learning methodology has allowed students of different degrees to be successfully integrated into research activities, including students from short-term undergraduate technical-professional programs. The main factor hindering the application of the methodology was the lack of technical skills and knowledge in sustainability concepts by the undergraduate students. Cooperation between the research team and students from the different level programs has been identified as a critical factor to overcome this limitation and attain successful learning.

Considering the barriers for the implementation of new curricular units or even to effectively include the sustainable topics in the HE curricula, particularly due to the short duration of both technical-professional programs and Bologna-adapted first and second level programs, projectbased learning supported by applied research may be an auxiliary and first approach to close the gap. In that way, the student participation in applied research projects focused on the sustainable development issues and a circular economy paradigm can overcome the lack of specific sustainability content in curricula. In addition, the applied research can be a driving force for spreading the sustainable development concepts across different programs, students and the community.

The participation of students in some activities was hindered by the partial incompatibility between the project's schedule and the programs' schedules. Students participation in research projects can benefit from future improvements in the coordination between programs' contents and projects' schedule.

The development of experimental activities as a basis for project-based learning can be the foundations for implementation of the sustainable development principles in the Portuguese HE curricula. Also by detailing the activities this project can be transferred to other universities and study programs.

\section{Acknowledgments}

The Valorbio project was partially supported by COMPETE2020 under the grant POCI-01-0145FEDER-23314, and by the consortia partners: Instituto Politécnico de Tomar, Instituto Politécnico de Coimbra, Instituto Politécnico de Portalegre and the company PALSER - Bionergia e Paletes, Lda.

The authors acknowledge the collaboration of the students of the Technical-Professional program in Environmental Quality, Bachelor program in Chemical and Biochemical Engineering and Master program in Chemical Technology, held at Instituto Politécnico de Tomar. Special thanks to the students André Farinha, Ana Batista, Carolina Masseno, Carolina Parra, Joel Nunes and Luís Santos.

The authors also acknowledge the Lab.IPT support, particularly, Alcino Serras, Carlos Ferreira, Isabel Silva and Vitor Gaspar, and the research fellows Ana Alves and Nuno Graça. 


\section{References}

Bourguignon, D. (2018). Water reuse: Setting minimum requirements. European Parliamentary Research Service www.europarl.europa.eu/RegData/etudes/BRIE/2018/625171/EPRS BRI(2018)625171 EN.pdf

Caniglia, G., John, B., Kohler, M., Bellina, L., Wiek, A., Rojas, C., Laubichler, M.D. and Lang, D. (2016), "An experience-based learning framework: Activities for the initial development of sustainability competencies", International Journal of Sustainability in Higher Education, Vol. 17, No. 6, pp. 827-852.

Cheang, C., So, W.-M., Zhan, Y. and Tsoi, K. (2017), "Education for sustainability using a campus eco-garden as a learning environment", International Journal of Sustainability in Higher Education, Vol. 18, No. 2, pp. 242-262.

Di Maria, F., Micale, C., Contini, S. and Morettini, E. (2016), "Impact of biological treatments of bio-waste for nutrients, energy and bio-methane recovery in a life cycle perspective", Waste Management, Vol. 82, pp. 86-95.

Díaz-Iso, A., Eizaguirre, A. and García-Olalla, A. (2019), "Extracurricular Activities in Higher Education and the Promotion of Reflective Learning for Sustainability", Sustainability, Vol. 11, No. 17 , pp. 1-18.

Dobson, H.E. and Tomkinson, C.B. (2012), "Creating sustainable development change agents through problem-based learning: Designing appropriate student PBL projects", International Journal of Sustainability in Higher Education, Vol. 13, No. 3, pp. 263-278.

Farinha, C., Caeiro, S. and Azeiteiro U. (2019), "Sustainability Strategies in Portuguese Higher Education Institutions: Commitments and Practices from Internal Insights", Sustainability, Vol. 11, No. 11, pp. 1-25 (article number: 3227 ).

Findler, F., Schönherr, N., Lozano, R., Reider, D. and Martinuzzi, A. (2019), "The impacts of higher education institutions on sustainable development: A review and conceptualization", International Journal of Sustainability in Higher Education, Vol. 20, No. 1, pp. 23-38.

Fonseca, L.M., Portela, A.R., Duarte, B., Queirós, J. and Paiva, L. (2018), "Mapping higher education for sustainable development in Portugal", Management \& Marketing: Challenges for the Knowledge Society, Vol., 13, No. 3, pp. 1064-1075.

Fuertes-Camacho, M.T., Graell-Martín, M., Fuentes-Loss, M. and Balaguer-Fàbregas, M.C. (2019), "Integrating Sustainability into Higher Education Curricula through the Project Method, a Global Learning Strategy", Sustainability, Vol. 11, No. 3, pp. 1-25 (article number: 767).

Gherghel, A., Teodosiu, C. and De Gisi, S. (2019), "A review on wastewater sludge valorisation and its challenges in the context of circular economy", Journal of Cleaner Production, Vol. 228, pp. 244-263.

Hero, L.-M. and Lindfors, E. (2019), "Students' learning experience in a multidisciplinary innovation project", Education+Training, Vol. 61, No. 4, pp. 500-522.

Kadlec, R. and Wallace, S. (2009), Treatment Wetlands, second ed., Edit. CRC Press/Taylor \& Francis Group, Boca Raton, USA. 
Leal Filho, W., Doni, F., Vargas, V.R., Wall, T., Hindley, A., Rayman-Bacchus, L., Emblen-Perry, K., Boddy, J. and Avila, L.V. (2019), "The integration of social responsibility and sustainability in practice: Exploring attitudes and practices in Higher Education Institutions", Journal of Cleaner Production, Vol. 220, pp. 152-166.

Mateus, D., Vaz, M., Capela, I. and Pinho, H. (2016), "The potential growth of sugarcane in constructed wetlands designed for tertiary treatment of wastewater", Water, Vol. 8, No. 93, pp. 1-14.

Mateus, D. and Pinho, H. (2018), "Screening of Solid Waste as Filler Material for Constructed Wetlands", Proceedings of the 9th International Conference on Environmental Science and Technology, IOP Conference Series: Earth and Environmental Science, Vol. 182, No. 012001, pp. 1-8.

Masi, F., Rizzo, A. and Regelsberger, M. (2018), "The role of constructed wetlands in a new circular economy, resource oriented, and ecosystem services paradigm", Journal of Environmental Management, Vol. 216, pp. 275-284.

Mendoza, J.M.F., Gallego-Schmid, A., Azapagic, A. (2019), "Building a business case for implementation of a circular economy in higher education institutions" Journal of Cleaner Production, Vol. 220, pp. 553-567.

Moretti, M., Van Dael, M., Malina, R. and Van Passel, S. (2018), "Environmental assessment of waste feedstock mono-dimensional and bio-refinery systems: Combining manure co-digestion and municipal waste anaerobic digestion", Journal of Cleaner Production, Vol. 171, pp. 954-961.

Nunes, B., Pollard, S., Burgess, P., Ellis, G., de los Rios, I. and Charnley, F. (2018), "University Contributions to the Circular Economy: Professing the Hidden Curriculum", Sustainability, Vol. 10, No. 8, pp. 1-24.

Pedersen, K., Pharo, E., Peterson, C. and Clark, G. (2017), "Wheels of change in higher education: A collaborative, multi-stakeholder project as a vehicle for sustainability education", International Journal of Sustainability in Higher Education, Vol. 18, No. 2, pp. 171-184.

Portuguese Law DL 236/1998. Diário da República, I Série-A No. 176, 1-8-1998 (in portuguese). https://data.dre.pt/eli/dec-lei/236/1998/08/01/p/dre/pt/html

Purcell, W., Henriksen, H. and Spengler, J. (2019), "Universities as the engine of transformational sustainability toward delivering the sustainable development goals: "Living labs" for sustainability", International Journal of Sustainability in Higher Education, Vol. ahead-of-print No. ahead-of-print, https://www.emeraldinsight.com/doi/full/10.1108/IJSHE-02-2019-0103

Shawe, R., Horan, W., Moles, R. and O'Regan, B. (2019) “Mapping of sustainability policies and initiatives in higher education institutes", Environmental Science \& Policy, Vol. 99, pp. 80-88.

Tangwanichagapong, S., Nitivattananon, V., Mohanty, B., Luang, K. and Visvanathan, C. (2017), "Greening of a campus through waste management initiatives: Experience from a higher education institution in Thailand", International Journal of Sustainability in Higher Education, Vol. 18, No. 2, pp. 203-217.

Wu, H., Zhang, J., Ngo, H., Guo, W., Hu, Z., Liang, S., Fan, J. and Liu, H. (2015a), "A review on the sustainability of constructed wetlands for wastewater treatment: Design and operation" Bioresource Technology, Vol. 175, pp. 594-601. 
Wu, H., Fan, J., Zhang, J., Ngo, H., Guo, W., Liang, S., Hu, Z. and Liu, H. (2015b), "Strategies and techniques to enhance constructed wetland performance for sustainable wastewater treatment", Environmental Science and Pollution Research, Vol. 22, No. 19, pp. 14637-14650.

Wu, S., Wallace, S., Brix, H., Kuschk, P., Kirui, W., Masi, F. and Dong, R. (2015c), "Treatment of industrial effluents in constructed wetlands: Challenges, operational strategies and overall performance", Environmental Pollution, Vol. 201, pp. 107-120.

\section{About the authors}

Dina Mateus is a Professor, Director of the master's degree in Chemical Technology and head of the Bioenergy and Applied Biotechnology Laboratory (www.biotec.ipt.pt) at the Polytechnic Institute of Tomar, Portugal. She holds a PhD in Biotechnology from the University of Lisbon. Her main research interests are constructed wetlands, environmental biotechnology and sustainability. Dina Mateus is the corresponding author and can be contacted at:

dinamateuspt.pt

Henrique Pinho is a Professor and the Head of the Smart Cities Research Center (www.ci2.ipt.pt) at the Polytechnic Institute of Tomar, Portugal. He holds a PhD in Chemical Engineering from the University of Lisbon. His main research interests are constructed wetlands, bioenergy and circular economy.

Isabel Nogueira is a Professor Coordinator in Mechanical Engineer and member of the Smart Cities Research Center at the Polytechnic Institute of Tomar, Portugal. She holds a PhD in Mechanical Engineer at École National Supérieur des Arts et Métiers (ENSAM) - Paris. Her main research interests are interfaces of material surfaces.

Manuel Rosa is a Professor at the Polytechnic Institute of Tomar, Portugal. MSc in Analytical Chemistry by the University of Aveiro and PhD in Environmental Sciences by the University of Salamanca. Current interests and lines of work in the fields of ecotoxicology and chemistry applied to the conservation and restauration.

Marco Cartaxo is a Professor, Erasmus and ECTS Coordinator of the degree in Chemical Technology and member of the Smart Cities Research Center at the Polytechnic Institute of Tomar, Portugal. He holds a PhD in Physical Chemistry from the University of Lisbon. His main research interests are electrochemistry and environmental chemistry.

Valentim Nunes is a Professor at the Polytechnic Institute of Tomar, Portugal. He holds a PhD in Chemical Technology from the University of Lisbon. His main research interests are the thermophysics of Fluids and Materials and applications in renewable energy. 